\title{
Coccygectomy Effects in Patients With Resistant Coccydynia in Ahvaz Hospitals From 2010 to 2014
}

\author{
Mohsen Khorrami ${ }^{1, *}$; Hamidreza Arti ${ }^{1}$; Davood Abbasi Moghadam ${ }^{1}$; Marzieh Meshki ${ }^{2}$ \\ ${ }^{1}$ Department of Orthopedics, Ahvaz Jundishapur University of Medical Sciences, Ahvaz, IR Iran \\ ${ }^{2}$ Aria Hospital, Ahvaz, IR Iran \\ *Corresponding author: Mohsen Khorrami, Department of Orthopedics, Ahvaz Jundishapur University of Medical Sciences, Ahvaz, IR Iran. Tel: +98-9161131149, Fax: +98-6133743097, \\ E-mail:khorami_md@yahoo.com
}

Received: October 27, 2014; Revised: Junuary 16, 2015; Accepted: Februry 27, 2015

Background: The majority of the cases of coccydynia occur in conjunction with either subluxated or hypermobile coccyx, and it has been proposed that this pathologic instability may cause chronic inflammatory changes.

Objectives: This study was done to evaluate the effect of coccygectomy in patients with resistant coccydynia after initial conservative therapy failure.

Patients and Methods: Between October 2010 and December 2013,13 patients with coccydynia underwent coccygectomy in the hospitals of Ahvaz city after a failed conservative therapy for at least 4 - 6 months. In order to evaluate the results, a questionnaire was obtained, including the extent of relief in the painful area, improvement in quality of life, intensity of pain in the sitting position, pain during daily activities, and the need for analgesics, according to the criteria described by Bayne.

Results: The patients were followed up for an average of 25.7 months. The results were good in 11 patients, excellent in 1 , and fair in only 1 patient. The excellent and good rates amounted to $92.2 \%$. No major complication was seen.

Conclusions: Coccygectomy is a successful treatment in patients unresponsive to conservative treatments for coccydynia.

Keywords: Coccydynia; Coccygectomy; Surgical Treatment; Non-Surgical Treatment

\section{Background}

The term coccydynia, first introduced by Simpson in the mid-nineteenth century, refers to symptoms of pain in the region of the coccyx (1). Derived from Greek word for "cuckoo" due to its resemblance to the beak of this bird, the coccyx comprises the most distal aspect of the vertebral column. It consists of three to five rudimentary vertebral units that, with the exception of the first coccygeal segment, are typically fused (1).

The majority of the cases of coccydynia occur in conjunction with either subluxated or hypermobile coccyx, and it has been proposed that this pathologic instability may cause chronic inflammatory changes. Many of these patients report a history of an antecedent traumatic event, which has been shown to be associated with coccygeal instability, particularly posterior subluxation (2).

The coccyx is more prominent in females than in males and coccygodynia is about five times more frequent in women (3). It has been postulated that women are more susceptible to coccydynia because tahe female pelvis is anatomically more prominent at the sacral and coccygeal level and they are exposed to childbirth trauma (3).

The body mass index (BMI) appears to influence the prevalence of coccydynia, as obesity is three times more common in patients with coccydynia than in the normal population (4).

Patients with normal and below-naormal weight are more likely to develop coccydynia consequent to lesion patterns other than posterior subluxation as their coccyges rotate in a more optimal fashion to lessen forces from falls and sitting (2).

Idiopathic coccydynia has been described in the absence of any obvious pathologic changes involving the coccyx, although this is considered a diagnosis of exclusion; in these patients the pain may actually result from spasticity or other abnormalities affecting the musculature of the pelvic floor. Coccydynia ranges from mild to severe and most of the time influences the quality of the patient's life. Patients with coccydynia most often present with pain in or around the coccyx without any significant low back pain, pain radiation, or referral pain (4). Classically, this pain is associated with sitting and is exacerbated by rising from a seated position (4).

Coccydynia usually responds to conservative measures such as anti-inflammatory drugs, using special pillows, or proper physiotherapy (5). However, when these measures fail, coccygectomy has been reported to be successful (6).

Copyright ( ) 2015, Ahvaz Jundishapur University of Medical Sciences. This is an open-access article distributed under the terms of the Creative Commons Attribution-NonCommercial 4.0 International License (http://creativecommons.org/licenses/by-nc/4.0/) which permits copy and redistribute the material just in noncommercial usages, provided the original work is properly cited. 


\section{Objectives}

The aim of this study was to evaluate the effects of coccygectomy on resistant coccydynia.

\section{Patients and Methods}

Forty-three patients with coccydynia were referred to the clinics in Ahvaz hospitals between October 2010 to December 2013 and after primary diagnostic evaluations underwent conservative treatment for coccydynia (e.g. special pillows, nonsteroidal anti-inflammatory drugs (NSAIDS), and physiotherapy for at least 4 to 6 months). A questionnaire, including the extent of relief in the painful area, improvement in quality of life, intensity of pain in the sitting position, pain during daily activities, and need for analgesics according to the criteria described by Bayne, was used (7). Thirty patients responded well to primary conservative therapy, while 13 patients underwent coccygectomy for resistant coccydynia. The patients' average age was 35 - 36 years ( 6 - 57 years old).

The cause of coccydynia was probably direct trauma in 9 (69.2\%) cases and idiopathic in 4 (30.7\%) (Table 1$)$.

The surgical procedure in all the patients was performed as follows:

With the patient under general anesthesia and in prone position over two parallel pillows, two large adhesive bands were placed in each gluteal area in order to expose the sacrococcygeal area. After disinfecting and draping the area, the sacrococcygeal area was exposed through a 4-cm midline incision over the sacrococcygeal junction and the intergluteal cleft. After removing the coccyx subperiosteally, efforts were made to ensure there was no penetration into the underlying viscera. After irrigation with $0.9 \%$ saline, the layers were sutured carefully and a simple dressing was placed. Prophylactic antibiotic (cephalosporin) was given 30 minutes before and up to 48 hours after surgery. All the patients were discharged on the first postoperative day. The surgical incision healed in 10 days in all the patients.

All the patients were followed up for 12 to 38 months. The clinical results were assessed, according to the criteria described by previous study (7). Complete relief of pain with no change in lifestyle or occupation was regarded as excellent. A good result implied occasional discomfort after prolonged sitting and minimal discomfort on digital examination as well as no analgesic requirements and no change in lifestyle or occupation. A fair result implied pain or discomfort on sitting for a short period of time and considerable pain on digital examination. Analgesics were occasionally required, but changes in lifestyle or occupation were fairly minimal. A poor result was defined as no improvement following surgery with the continuous need for analgesics.

Descriptive tests were employed to analyze the data using the Statistical Package for the Social Sciences (SPSS 20) software.

\section{Results}

After initial conservative therapy for 43 patients, 30 cases responded well according to the Bayne criteria. Thirteen patients showed fair or poor results (8 (61.5\%) patients fair and 5 (38.5\%) with poor results) and were elected for surgery (Table 2). After coccygectomy, 11 (84.4\%) patients had good results, 1 (7.6\%) had an excellent result, and only 1 (7.6\%) had a fair result. Most of these patients (76.9\%) were women and the majority of them (61.4\%) were housewives. Additionally, there were 2 students, 1 nurse, and 1 employee (Table 1). The mean BMI was 26.9 (range $=20.9$ to 31.9 ) (Table 1$)$.

\begin{tabular}{ll}
\hline Table 1. Demographic Characteristics ${ }^{\mathrm{a}}$ & \\
\hline Variables & Values \\
\hline Gender & \\
\hline Female & $10(76.9)$ \\
\hline Male & $3(23.1)$ \\
\hline Pathology & \\
\hline Direct trauma & $9(69.3)$ \\
\hline Idiopathic & $4(30.7)$ \\
\hline Age, $\mathbf{y}$ & \\
\hline $0-10$ & $1(7.6)$ \\
\hline $20-30$ & $3(23.1)$ \\
\hline $30-40$ & $4(30.7)$ \\
\hline $40-50$ & $2(15.5)$ \\
\hline $50-60$ & $3(23.1)$ \\
\hline Body mass index, $\mathbf{k g} / \mathbf{m}^{2}$ & \\
\hline $20-40$ & $3(23.1)$ \\
\hline $24-30$ & $8(61.4)$ \\
\hline$>30$ & $2(15.5)$ \\
\hline Occupation & $1(7.6)$ \\
\hline Housewifery & \\
\hline Student & \\
\hline Nurse & \\
\hline Employee & \\
\hline
\end{tabular}

a Values are presented as No.(\%).

Table 2. Results of Conservative Therapy Versus Surgery ${ }^{\mathrm{a}}$

\begin{tabular}{lcc}
\hline Results & Before Surgery & After Surgery \\
\hline Excellent & $0(0)$ & $1(7.6)$ \\
Good & $0(0)$ & $11(84.6)$ \\
Fair & $8(61.5)$ & $1(7.6)$ \\
Weak & $5(38.5)$ & $0(0)$ \\
\hline
\end{tabular}

a Values are presented as No.(\%). 


\section{Discussion}

Traumatic coccydynia causes symptoms similar to pericoccygeal soft tissue lesions, pelvic floor muscle spasms, referred pain from lumbar pathology, arachnoiditis of the sacral nerve roots, local post-traumatic lesions, somatization, pain caused by osteoarthritis, or subluxation in the sacrococcygeal joint (8). Coccydynia should be further differentiated from pain caused by a variety of perianal pathologies such as hemorrhoids, fissures, perianal fistulas, anorectal abscesses, and pilonidal sinuses (8).

In this study, similar to previously reported studies, coccydynia was more common in women than men (9).

According to literature, the BMI influences the prevalence of coccydynia (4). Likewise, our results showed that most of the patients $(76.9 \%)$ were overweight or obese (Table 1).

The present study demonstrated no relation between the prevalence of coccydynia and the patients' occupations.

Among our study population, $84.4 \%$ of the patients showed good, 7.6\% had excellent, and only 1 had fair responses to coccygectomy (3), which chimes in with other previous studies (10-15).

Whereas some authors have reported good results after coccygectomy but with high rates of wound infection (16, 17), the results of the present study showed no postoperative infection.

There has been a report on a better result in traumatically-induced coccydynia than in idiopathic coccydynia following surgical intervention (18). The same result was obtained in this study, and the only patient with a fair result after coccygectomy had idiopathic coccydynia.

Although the number of cases in this study is small, the effectiveness of coccygectomy for coccydynia is evident. The results of this study suggest that coccygectomy is a feasible option in patients with coccydynia and no response to conservative treatments. Also, careful selection of appropriate patients for coccygectomy and prophylactic antibiotics are crucial in successful outcomes.

In conclusion, coccydynia is a discomforting and disabling problem, especially in women. Differential diagnoses should be made with a variety of regional patholo- gies and when conservative modalities are exhausted, surgery can confer relief in the majority of cases.

\section{Acknowledgements}

Our special thanks go to the members of the Clinical Development Research Unit of Golestan Hospital for their expertise.

\section{References}

1. Patel R, Appannagari A, Whang PG. Coccydynia. Curr Rev Musculoskelet Med. 2008;1(3-4):223-6.

2. Maigne JY, Doursounian L, Chatellier G. Causes and mechanisms of common coccydynia: role of body mass index and coccygeal trauma. Spine (Phila Pa 1976). 2000;25(23):3072-9.

3. Hellberg S, Strange-Vognsen HH. Coccygodynia treated by resection of the coccyx. Acta Orthop Scand.1990;61(5):463-5.

4. Fogel GR, Cunningham PY, Esses SI. Coccygodynia: evaluation and management. J Am Acad Orthopaed Surg. 2004;12(1):49-54.

5. Maigne JY, Chatellier G. Comparison of three manual coccydynia treatments: a pilot study. Spine (Phila Pa 1976). 2001;26(20):E479-83.

6. Pyper JB. Excision of the coccyx for coccydynia; a study of the results in twenty-eight cases. J Bone Joint Surg Br. 1957;39-B(4):733-7.

7. Albrecht S, Hicks MJ, Antalffy B. Intracoccygeal and pericoccygeal glomus bodies and their relationship to coccygodynia. Surgery. 1994;115(1):1-6.

8. De Andres J, Chaves S. Coccygodynia: a proposal for an algorithm for treatment.J Pain. 2003;4(5):257-66.

9. Peyton FW. Coccygodynia in women. India Medi J India State Med Assoc. 1988;81(8):697-8.

10. Alceu Gomes C, Guaracy Carvalho F, Luciano Barboza DS Coccydynia: surgical treatment. Acta Ortopedica Brasileira. 2002;10(4):26-30.

11. Pennekamp PH, Kraft CN, Wallny T, Schmitt O, Diedrich O. [Coccygectomy in the treatment of coccygodynia].Z Orthop Ihre Grenzgeb. 2003;141(5):578-82.

12. Valen B, Bringedal K. Coccygectomy for coccygodynia. Tidsskrift for den Norske laegeforening tidsskrift for praktisk medicin ny raekke. 1999;119(10):1429-30.

13. Balain B, Eisenstein SM, Alo GO, Darby AJ, Cassar-Pullicino VN Roberts SE, et al. Coccygectomy for coccydynia: case series and review of literature. Spine (Phila Pa 1976). 2006;31(13):E414-20.

14. Grosso NP, van Dam BE. Total coccygectomy for the relief of coccygodynia: a retrospective review. J Spin Disord. 1995;8(4):328-30.

15. Kersey PJ. Non-operative management of coccygodynia. Lancet 1980;1(8163):318

16. Wood KB, Mehbod AA. Operative treatment for coccygodynia. J Spin Disord Tech. 2004;17(6):511-5.

17. Hodges SD, Eck JC, Humphreys SC. A treatment and outcomes analysis of patients with coccydynia. Spine J. 2004;4(2):138-40.

18. Pennekamp PH, Kraft CN, Stutz A, Wallny T, Schmitt O, Diedrich O. Coccygectomy for coccygodynia: does pathogenesis matter? J Trauma. 2005;59(6):1414-9. 